\title{
Cornual pregnancy and interstitial pregnancy
}

\author{
Kornual ve interstisyal gebelik
}

\author{
Cemil Yaman \\ Department of Obstetrics and Gynecology, General Hospital of Linz, Linz, Austria
}

Dear editor;

Comments regarding the published case report from Günenç et al "Laparoscopic surgery of interstitial (cornual) pregnancy 2009 11-2: 102-4 in TGGA" Authors reported: "The terms cornual and interstitial pregnancy are used synonymously (page 102, line 17) to define pregnancy implanted in the interstitial part of the fallopian tube which is the proximal portion that is embodied within the muscular wall of the uterus".

\section{Comments}

In the North American literature and in a small number of European literature, the terms "interstitial pregnancy" and "cornual pregnancy" are used synonymously. However, it seems that recent studies indicate differences between these two pregnancies (1-3).

Cornual pregnancy is a pregnancy in one horn of a bircornuated uterus or, by extension, in one half of a septated or subseptated uterus. It may be that a bicornuate uterus predisposes the embryo to high implantation. Intramural pregnancies occur when the embryo implants in and is completely surrounded by myometrium clearly removed from either the uterine cavity or the interstitial portion of the tube.

The pregnancy is referred to as an Interstitial pregnancy if the implantation occurs in the interstitial part of the fallopian tube that is embodied within the muscular wall of the uterus. It is not associated with uterine anomalies.
Interstitial pregnancies often progress without symptoms until a rupture occurs later than other tubal pregnancies. The management of cornual pregnancy can be complicated because of malformations $(1,2)$. Due to these facts there is a need to differentiate between these pathologies. Furthermore, the occurrence of an angular pregnancy, which is distinguished from cornual and interstitial pregnancy anatomically by its position in relation to the round ligament, should be taken into the diagnostic considerations. Unlike the interstitial and cornual pregnancies, angular pregnacies may have a favorable outcome (4).

\section{Conflict of interest}

No conflict of interest is declared by authors.

\section{References}

1. Malinowski A, Bates SK. Semantics and pitfalls in the diagnosis of cornual/interstitial pregnancy. Fertil Steril. 2006; 86: 1764.

2. Lau S, Tulandi T. Conservative medical and surgical management of interstitial ectopic pregnancy. Fertil Steril. 1999; 72: 207-15.

3. Mavrelos D, Sawyer E, Helmy S, Holland TK, Ben-Nagi J, Jurkovic D. Ultrasound diagnosis of ectopic pregnancy in the non-communicating horn of a unicornuate uterus (cornual pregnancy). Ultrasound Obstet Gynecol. 2007; 30: 765-70. [CrossRef]

4. Jansen RP, Elliott PM. Angular intrauterine pregnancy. Obstet Gynecol. 1981; 58: 167-75. 